\title{
Prevalence of frailty in elderly patients with renal diseases
}

\author{
Eman Mahmoud Abdelhamid, Salma Mohamed Samir El Said, Mohamed Shawky khater, \\ Suzan Mounir Ali \\ Geriatrics and Gerontology Department, Faculty of Medicine, Ain Shams University
}

\begin{abstract}
Background: Frailty, the state of increase vulnerability to physical stressors as a result of progressive and sustained degeneration in multiple physiological systems, is common in those with chronic kidney disease with prevalence more than $60 \%$ in dialysis-dependent CKD patients.
\end{abstract}

Aim: to determine the prevalence of frailty in patient with renal disease.

Methods: A cross section study on 100 participants, males and females $\geq 60$ years from patients in Ain Shams University hospital, 50 patients on regular hemodialysis and 50 patients with chronic renal impairment. The estimated glomerular filtration rate $(\mathrm{ml} / \mathrm{min} / 1.73 \mathrm{~m} 2)$ determined according to serum creatinine level, with exclusion of GFR $\geq$ 60. They completed comprehensive geriatrics assessment and modified fried criteria for assessing frailty by; selfreported weight loss, low grip strength, exhaustion, slow gait speed and low physical activity. Multidimensional assessment of fatigue (MAF) was performed.

Results: There were 57 males, 43 females, mean age 66.9, 79\% were frail, 65\% illiterates, 67\% married, 32\% smokers, self-reported exhaustion and low activity were statistically significance between CKD and hemodialysis group. Frail participants were divided in to two groups; CKD frail group $n=33$ and hemodialysis frail group $n=46$. Only exhaustion criteria had statistically significance difference between CKD frail and hemodialysis frail group, $87 \%$ of hemodialysis frail were MAF positive and $81.8 \%$ in CKD frail.

Conclusion: Frailty is common in patient with chronic kidney disease and its prevalence increase as the disease advance and become more severe in hemodialysis patients. Self-reported exhaustion was the initial indicator of frailty.

Keywords: Frailty, CKD, hemodialysis, multi-dimensional assessment of fatigue, obesity.

\section{Background}

The population aged 65 years old and older is expected to be more than double between 2012 and 2060, with continuing increasing in age related co-morbidities as frailty (Aguirre and Villareal, 2015).

Frailty is common in those with chronic kidney disease (CKD). The prevalence of frailty in the communitydwelling older adult population is reported to be $11 \%$, whereas studies have reported a frailty prevalence of $>60 \%$ in dialysis dependent CKD patients (Bao et al., 2012; Collard et al., 2012).

Frailty is independently linked with adverse clinical outcomes in all stages of CKD and has been repeatedly shown to be associated with an increased risk of mortality and hospitalization (Bao et al., 2012; Collard et al., 2012l Shen et al., 2017).

\section{Materials and Methods}

A cross-sectional study held on 100 participants, Males and Females aging 60 years or more recruited from inpatient ward and outpatient clinics in Ain Shams University Hospital, 50 patients on regular dialysis, 50 patients diagnosed with chronic renal impairment with excluding patients with estimated glomerular filtration rate more than $60 \mathrm{mg} / \mathrm{min} / 1.73 \mathrm{~m}^{2}$.

All participants were subjected to verbal consent for acceptance to participate in the study and completed a comprehensive geriatric assessment in the form of; history taking (complete medical history), cognitive functional assessment (Mini-mental status examination) (El-Okl et al., 2002). and screening for depression by Geriatric Depression Scale (GDS-15) (Metwally, A. S., 
et al., 1998). Functional assessment by (ADL) (Katz et al., 1963) and (IADL) (Lawton and Brody, 1969). Assessment of Frailty by modified Fried criteria (Fried et al., 2001); self-reported weight loss, low grip strength, exhaustion, slow gait speed and low physical activity. Assessment of gait speed by the Time up and go test (Podsiadlo and Richardson, 1991).

Assessment of fatigue by Multidimensional Assessment of Fatigue (MAF) (Belza BL, 1995), assessment of balance by one leg balance test (Kouvelioti et al., 2015), calculation of body mass index. Laboratory data collected from the participants and analyzed in Ain Shams University Hospital central labs (complete blood picture, serum creatinine, calcium, phosphorus, sodium, potassium and glomerular filtration rate by Cockcroft gault equation.

The frail participants were (33 participants) in CKD group and (46 participants) hemodialysis group.

Statistical Analysis: Data were collected, revised, coded and entered to the Statistical Package for Social Science (IBM SPSS) version 20. The quantitative data were presented as mean, standard deviations and ranges when their distribution found parametric and qualitative data were presented as number and percentages.

The comparison between groups regarding qualitative data was done by using Chi-square test and/or Fisher exact test only when the expected count in any cell was less than 5 .

The comparison between two independent groups with quantitative data and parametric distribution was done using Independent t-test while data with nonparametric distribution was compared using MannWhitney test, and Generalized linear regression was done to assess predictors, among the assessment tools of frailty domains.

The confidence interval was set to $95 \%$ and the margin of error accepted was set to $5 \%$. The p-value was considered significant as the following:

$\mathrm{P}>$ 0.05: Non-significant, $\mathrm{P}<0.05$ : Significant, $\mathrm{P}<$ 0.01: Highly significant

\section{Results:}

The study sample consisted of 100 elderly participants; 50 participants were on hemodialysis and the other half had chronic renal disease. The mean age was $66.89 \pm 6.41$. It was $68.20 \pm 7.02$ in CKD group which was higher than the mean age of the hemodialysis group which was $65.58 \pm 5.49$ with statistically significant difference found between them. $57 \%$ of our participants were males, $43 \%$ were females. Most of the study subject was illiterates $(65 \%)$. $67 \%$ of our participants were married.67\% were nonsmokers, $1 \%$ were ex-smoker. (Table 1)

The prevalence of frailty was $79 \%$ of all studied sample. It was $92 \%$ in hemodialysis group and $66 \%$ of CKD group. $21 \%$ of study population was pre frail. Mean frailty score in study population was $3.65 \pm 1.10$ which was more in hemodialysis group $(4.02 \pm 0.84)$ than in CKD group $(3.28 \pm 1.21)$.

As regard frailty criteria, the mean score of exhaustion criteria and low physical activity were more in hemodialysis group than in CKD group which had high statistically significance difference found between them. It's found that $20 \%$ of cases had significant weight loss which was more prevalent in hemodialysis group, $97 \%$ of cases had slow walking speed and weak grip strength which was more prevalent in hemodialysis group. (Table 2)

Illustrating frailty criteria between CKD frail group (33 participants) and hemodialysis frail group (46 participants). In hemodialysis frail group $26.1 \%$ had significant weight loss, $91.3 \%$ were physically inactive and all the participants had slow gait speed and weak hand strength.

In CKD frail group $24.2 \%$ has significant weight loss, $90.9 \%$ were physically inactive $97 \%$ had slow gait speed and all participants had weak hand strength. Mean score of exhaustion criteria was more in hemodialysis frail group than in CKD group which had statistically significant difference between both groups .(Table 3)

Lab difference between CKD frail and hemodialysis frail group was as following: mean hemoglobin level and mean serum $\mathrm{Ca}$ were more in CKD frail group than in hemodialysis frail group. While mean serum phosphorous level and serum potassium level were more in hemodialysis frail group.

For assessment of fatigue by using multidimensional assessment of fatigue .It is found that $87 \%$ of hemodialysis frail participants were MAF positive, while it was $81.8 \%$ in CKD frail participants.(Table 4)

For assessing predictors and protectors of frailty; logistic regression analysis was done and showed that age $>65$, widows, osteoporosis, MMSE $\leq 27$, depression, dependence in ADL, exhaustion, slow speed, abnormal TUG, low GFR, Fatigue) all of those are predictors of frailty. While DM, high education, independence in ADL and IADL, and normal balance are protectors from frailty. (Table 5) 
Table 1. Comparison between CKD \& hemodialysis group regarding Demographic data

\begin{tabular}{|c|c|c|c|c|c|c|c|}
\hline & Total & CKD & Hemodialysis & \multirow[t]{2}{*}{ Test value } & \multirow{2}{*}{$\begin{array}{l}\text { P- } \\
\text { value }\end{array}$} & \multirow[t]{2}{*}{ Sig. } \\
\hline & & No. $=100$ & No. $=\mathbf{5 0}$ & No. $=\mathbf{5 0}$ & & & \\
\hline Age & Mean \pm SD & $66.89 \pm 6.41$ & $68.20 \pm 7.02$ & $65.58 \pm 5.49$ & $2.079 \bullet$ & 0.040 & $\mathbf{S}$ \\
\hline \multirow[t]{2}{*}{ Gender } & Male & $57(57.0 \%)$ & $33(66.0 \%)$ & $24(48.0 \%)$ & \multirow[t]{2}{*}{$3.305 *$} & \multirow[t]{2}{*}{0.069} & \multirow[t]{2}{*}{ NS } \\
\hline & Female & $43(43.0 \%)$ & $17(34.0 \%)$ & $26(52.0 \%)$ & & & \\
\hline \multirow[t]{5}{*}{ Education } & Illiterate & $65(65.0 \%)$ & $30(60.0 \%)$ & $35(70.0 \%)$ & \multirow[t]{5}{*}{$10.940 *$} & \multirow[t]{5}{*}{0.027} & \multirow[t]{5}{*}{$\mathbf{S}$} \\
\hline & Primary school & $2(2.0 \%)$ & $1(2.0 \%)$ & $1(2.0 \%)$ & & & \\
\hline & Prep school & $5(5.0 \%)$ & $0(0.0 \%)$ & $5(10.0 \%)$ & & & \\
\hline & Diploma & $10(10.0 \%)$ & $5(10.0 \%)$ & $5(10.0 \%)$ & & & \\
\hline & Highly educated & $18(18.0 \%)$ & $14(28.0 \%)$ & $4(8.0 \%)$ & & & \\
\hline $\begin{array}{l}\text { Marital } \\
\text { status }\end{array}$ & Married & $67(67.0 \%)$ & $32(64.0 \%)$ & $35(70.0 \%)$ & $0.407 *$ & 0.523 & NS \\
\hline \multirow{2}{*}{$\begin{array}{l}\text { Special } \\
\text { habits }\end{array}$} & Smoker & $32(32.0 \%)$ & $20(40.0 \%)$ & $12(24.0 \%)$ & \multirow[t]{2}{*}{$4.209 *$} & \multirow[t]{2}{*}{0.122} & \multirow[t]{2}{*}{ NS } \\
\hline & Ex-smoker & $1(1.0 \%)$ & $1(2.0 \%)$ & $0(0.0 \%)$ & & & \\
\hline
\end{tabular}

P-value >0.05: Non significant (NS); P-value <0.05: Significant (S); P-value< 0.01: highly significant (HS) *:Chi-square test; $\neq:$ Mann Whitney test.

Table 2: Comparison between CKD group and hemodialysis group regarding frailty criteria

\begin{tabular}{|c|c|c|c|c|c|c|c|}
\hline \multirow{2}{*}{\multicolumn{2}{|c|}{ Frailty criteria }} & Total & CKD & Hemodialysis & \multirow[t]{2}{*}{ Test value } & \multirow{2}{*}{$\begin{array}{l}P \text { - } \\
\text { value }\end{array}$} & \multirow[t]{2}{*}{ Sig. } \\
\hline & & No. $=100$ & No. $=\mathbf{5 0}$ & No. $=\mathbf{5 0}$ & & & \\
\hline \multicolumn{8}{|l|}{ Al weigh loss } \\
\hline $\begin{array}{l}\text { Un intended weight } \\
\text { loss }\end{array}$ & Positive & $20(20.0 \%)$ & $8(16.0 \%)$ & $12(24.0 \%)$ & & & \\
\hline BMI & Mean \pm SD & $27.70 \pm 6.21$ & 26.975 .29 & $28.43 \pm 7.00$ & $-1.176 \bullet$ & 0.243 & NS \\
\hline \multicolumn{8}{|l|}{$\mathbf{B} \backslash$ Exhaustion criteria } \\
\hline Q1 & Mean \pm SD & $1.50 \pm 1.11$ & $1.08 \pm 1.03$ & $1.92 \pm 1.05$ & $-3.844 \%$ & 0.000 & HS \\
\hline Q2 & Mean \pm SD & $1.55 \pm 1.10$ & $1.12 \pm 1.06$ & $1.98 \pm 0.96$ & $-3.934 \%$ & 0.000 & HS \\
\hline ClSlow speed & Positive & $97(97.0 \%)$ & $47(94.0 \%)$ & $50(100.0 \%)$ & 3.093* & 0.079 & NS \\
\hline D\weakness & Positive & $97(97.0 \%)$ & $48(96.0 \%)$ & $49(98.0 \%)$ & $0.344 *$ & 0.558 & NS \\
\hline E/low activity & Positive & $72(72.0 \%)$ & $30(60.0 \%)$ & $42(84.0 \%)$ & 7.143* & 0.008 & HS \\
\hline SCORE & Mean \pm SD & $3.65 \pm 1.10$ & $3.28 \pm 1.21$ & $4.02 \pm 0.84$ & $-3.138 \%$ & 0.002 & HS \\
\hline \multirow[t]{2}{*}{ Frail } & Pre frail & $21(21.0 \%)$ & $17(34.0 \%)$ & $4(8.0 \%)$ & \multirow[t]{2}{*}{$10.187 *$} & \multirow[t]{2}{*}{0.001} & \multirow[t]{2}{*}{ HS } \\
\hline & Frail & $79(79.0 \%)$ & $33(66.0 \%)$ & $46(92.0 \%)$ & & & \\
\hline
\end{tabular}

P-value >0.05: Non-significant (NS); P-value <0.05: Significant (S); P-value< 0.01: highly significant (HS) *:Chi-square test; \$: Mann Whitney test.

Q1 how often in the last week did you feel that everything you did was an effort.

Q2 how often in the last week did you feel that you could not get out. 
Table (3): Comparison between frail CKD \& frail hemodialysis regarding frailty criteria

\begin{tabular}{|c|c|c|c|c|c|c|}
\hline \multirow{2}{*}{\multicolumn{2}{|c|}{ Frailty criteria }} & CKD frail & Hemodialysis frail & \multirow[t]{2}{*}{ Test value } & \multirow[t]{2}{*}{ P-value } & \multirow[t]{2}{*}{ Sig. } \\
\hline & & No. $=33$ & No. $=46$ & & & \\
\hline \multicolumn{7}{|l|}{ A| weigh loss } \\
\hline Un intended weight loss & Positive & $8(24.2 \%)$ & $12(26.1 \%)$ & & & \\
\hline BMI & Mean \pm SD & $27.08 \pm 6.04$ & $28.87 \pm 7.12$ & -1.176 & 0.243 & NS \\
\hline \multicolumn{7}{|l|}{ B\Exhaustion criteria } \\
\hline Q1 & Mean \pm SD & $1.64 \pm 0.82$ & $2.00 \pm 0.99$ & -1.726 & 0.088 & NS \\
\hline Q2 & Mean \pm SD & $1.70 \pm 0.85$ & $2.09 \pm 0.84$ & -2.030 & 0.046 & $\mathrm{~S}$ \\
\hline ClSlow speed & Positive & $32(97.0 \%)$ & $46(100.0 \%)$ & 1.412 & 0.235 & NS \\
\hline D\weakness & Positive & $33(100.0 \%)$ & $46(100.0 \%)$ & - & - & - \\
\hline E/low activity & Positive & $30(90.9 \%)$ & $42(91.3 \%)$ & 0.004 & 0.951 & NS \\
\hline Score & Mean \pm SD & $4.06 \pm 0.56$ & $4.20 \pm 0.62$ & 1.147 & 0.233 & NS \\
\hline
\end{tabular}

P-value >0.05: Non-significant (NS); P-value <0.05: Significant (S); P-value < 0.01: highly significant (HS) *:Chi-square test; $\$$ : Mann Whitney test.

Q1 how often in the last week did you feel that everything you did was an effort.

Q2 how often in the last week did you feel that you could not get out.

Table (4): Comparison between CKD frail and hemodialysis frail regarding lab findings and multi-dimensional assessment of fatigue

\begin{tabular}{|c|c|c|c|c|c|c|}
\hline \multirow{2}{*}{\multicolumn{2}{|c|}{ Labs }} & CKD frail & Hemodialysis frail & \multirow[t]{2}{*}{ Test value } & \multirow[t]{2}{*}{ P-value } & \multirow[t]{2}{*}{ Sig. } \\
\hline & & No. $=33$ & No. $=46$ & & & \\
\hline HB & Mean \pm SD & $9.71 \pm 1.37$ & $9.20 \pm 1.29$ & 1.666 & 0.100 & NS \\
\hline ser Ca & Mean \pm SD & $8.72 \pm 0.59$ & $8.36 \pm 0.81$ & 2.182 & 0.032 & $\mathrm{~S}$ \\
\hline serPo4 & Mean \pm SD & $4.04 \pm 0.88$ & $4.95 \pm 1.10$ & -3.914 & 0.000 & HS \\
\hline ser $\mathrm{Na}$ & Mean \pm SD & $136.76 \pm 6.30$ & $136.30 \pm 7.39$ & 0.285 & 0.776 & NS \\
\hline ser $\mathbf{K}$ & Mean \pm SD & $4.55 \pm 0.66$ & $4.56 \pm 0.79$ & -0.065 & 0.948 & NS \\
\hline SER Cr & Mean \pm SD & $2.90 \pm 1.08$ & $5.53 \pm 1.52$ & -8.514 & 0.000 & $\mathrm{HS}$ \\
\hline \multirow[t]{3}{*}{ GFR } & G3B & $11(33.3 \%)$ & $0(0.0 \%)$ & \multirow[t]{3}{*}{79.000} & \multirow[t]{3}{*}{0.000} & \multirow[t]{3}{*}{ HS } \\
\hline & G4 & $22(66.7 \%)$ & $0(0.0 \%)$ & & & \\
\hline & G5 & $0(0.0 \%)$ & $46(100.0 \%)$ & & & \\
\hline \multirow[t]{2}{*}{ MAF } & Negative & $6(18.2 \%)$ & $6(13.0 \%)$ & \multirow[t]{2}{*}{0.394} & \multirow[t]{2}{*}{0.530} & \multirow[t]{2}{*}{$\mathrm{NS}$} \\
\hline & Positive & $27(81.8 \%)$ & $40(87.0 \%)$ & & & \\
\hline
\end{tabular}

P-value >0.05: Non significant (NS); P-value <0.05: Significant (S); P-value< 0.01: highly significant (HS) *:Chi-square test; \$: Mann Whitney test.

Table (5): Logistic regression analysis for the predictors of frail cases in all CKD cases

\begin{tabular}{|c|c|c|c|c|c|c|c|}
\hline & \multirow[t]{2}{*}{ B } & \multirow[t]{2}{*}{ S.E. } & \multirow[t]{2}{*}{ Wald } & \multirow[t]{2}{*}{ P-value } & \multirow{2}{*}{$\begin{array}{c}\text { Odds ratio } \\
\text { (OR) }\end{array}$} & \multicolumn{2}{|c|}{ 95\% C.I. for OR } \\
\hline & & & & & & Lower & Upper \\
\hline Age $>65$ & 1.138 & 0.560 & 4.134 & 0.042 & 3.120 & 1.042 & 9.343 \\
\hline Marital status & 1.814 & 0.778 & 5.433 & 0.020 & 6.135 & 1.335 & 28.205 \\
\hline DM & -1.355 & 0.665 & 4.151 & 0.042 & 0.258 & 0.070 & 0.950 \\
\hline OP & 1.914 & 1.057 & 3.280 & 0.070 & 6.780 & 0.854 & 53.803 \\
\hline MMSE < $=27$ & 2.205 & 0.548 & 16.201 & 0.000 & 9.073 & 3.100 & 26.553 \\
\hline Orientation $<=9$ & 2.022 & 0.777 & 6.773 & 0.009 & 7.557 & 1.648 & 34.660 \\
\hline Reading & -1.739 & 0.526 & 10.922 & 0.001 & 0.176 & 0.063 & 0.493 \\
\hline Writing & -1.739 & 0.526 & 10.922 & 0.001 & 0.176 & 0.063 & 0.493 \\
\hline Drawing & -1.726 & 0.545 & 10.050 & 0.002 & 0.178 & 0.061 & 0.517 \\
\hline GDS (Depression) & 0.985 & 0.502 & 3.848 & 0.050 & 2.678 & 1.001 & 7.167 \\
\hline $\mathrm{ADL} \leq \mathbf{5}$ & 2.559 & 1.050 & 5.934 & 0.015 & 12.917 & 1.649 & 101.193 \\
\hline Transportation & -2.818 & 1.049 & 7.213 & 0.007 & 0.060 & 0.008 & 0.467 \\
\hline Exhaustion criteria & 4.183 & 0.817 & 26.226 & 0.000 & 65.550 & 13.223 & 324.948 \\
\hline Slow speed & 2.105 & 1.251 & 2.832 & 0.092 & 8.211 & 0.707 & 95.362 \\
\hline TUGO Score & 1.611 & 0.505 & 10.196 & 0.001 & 5.008 & 1.863 & 13.464 \\
\hline Balance Score & -2.006 & 0.555 & 13.045 & 0.000 & 0.135 & 0.045 & 0.400 \\
\hline$H B<=10.3$ & 2.287 & 0.558 & 16.777 & 0.000 & 9.844 & 3.296 & 29.403 \\
\hline SER Cr > 3.7 & 1.495 & 0.561 & 7.108 & 0.008 & 4.461 & 1.486 & 13.390 \\
\hline GFR & 1.106 & 0.332 & 11.080 & 0.001 & 3.023 & 1.576 & 5.798 \\
\hline MAF & 4.716 & 1.072 & 19.365 & 0.000 & 111.667 & 13.671 & 912.104 \\
\hline
\end{tabular}

P-value >0.05: Non significant (NS); P-value <0.05: Significant (S); P-value< 0.01: highly significant (HS) *:Chi-square test; \$: Mann Whitney 


\section{DISCUSSION}

The prevalence of frailty of the current study was $79 \%$. It was more prevalent in hemodialysis group. This outcome is higher than that reported by Song et al. (2020).

Johanson et al. (2007) showed that the prevalence of frailty in participants aging from 60 to 70 years was (74.2\%) from 70 to 80 years was $(78.1 \%)$, and more than 80 year was $(78.8 \%)$. This result is near to ours in age group more than 60 years old.

As regard frailty criteria, the mean exhaustion criteria and low activity were more in hemodialysis group than in CKD group which had high statistically significance difference found between them. It's found that $20 \%$ of cases had significant weight loss which was more prevalent in hemodialysis group, $97 \%$ of cases had slow walking speed and weak grip strength which was more prevalent in hemodialysis group.

In hemodialysis frail group $26 \%$ had significant weight loss, $91.3 \%$ were physically inactive and all the participants had slow gait speed and weak hand strength.

In CKD frail group $24.2 \%$ has significant weight loss, $90.9 \%$ were physically inactive $97 \%$ had slow gait speed and all participants had weak hand strength. Mean score of exhaustion criteria was more in hemodialysis frail group than in CKD group.

It comes with Roshanravan et al. (2012) in an observational study held on 336 participants with CKD completed fried criteria for frailty showed that the most common frailty component in individuals with CKD were low physical activity, exhaustion and slow gait speed.

Our results showed that there were positive correlation between age as in song et al. (2020); Mansur et al. (2007), depression as with (Andersen et al., 2005; Laursen et al., 2007; Feng et al., 2014), Exhaustion criteria which comes with (Roshanravan et al., 2012), ser $(\mathrm{k})$, ser $(\mathrm{Cr})$ which comes with (Wilhem-leen et al., 2009) and frailty score.

While there was inverse correlation between MMSE; orientation, recall and $\mathrm{Hb}$ level which comes with (Dowling, 2007; Chaves et al., 2002) and frailty. Also there was highly statistically significance between frail score and educational level, MMSE (reading, writing, drawing) While there was statistically significance between frail score and special habits which comes with (Takeuchi et al., 2018), DM which comes with (Mousavi et al., 2012), HF which comes with (Sarnak et al., 2003). Also there was highly statistically significance between frail score and ADL dependency regarding bathing, Dressing, transferring and transportation from IADL, while there was statistically significance between frail score and toileting which comes with (xue, 2011). Transportation only from IADL had highly statistically significance.

There was high statistically significance relation between frail score and TUG, and balance which comes with (Mulasso et al., 2017), GFR (Wilhem-leen et al., 2009), MAF which comes with (McCann et al., 2000); While there was statistically significance regarding BMI a $\mathrm{u}$ shaped relation which is supported by (Hubbard et al., 2010).

Logistic regression showed that (age > 65, marital status "widows, osteoporosis, MMSE $\leq 27$, orientation $\leq 9$, depression, $\mathrm{ADL} \leq 5$, exhaustion criteria, slow speed, TUG "Independent \& dependent" , $\mathrm{Hb} \leq 10.3$, serum $\mathrm{Cr}>3.7$, low GFR, MAF ) all of those are predictors of frailty; while ability of reading, writing, drawing, ability of transport, and normal balance are protectors from frailty.

\section{Conclusion}

Prevalence of frailty was $79 \%$ in the studied sample. Frailty is common in patient with chronic kidney disease and its prevalence increase as the disease advance and become more severe in hemodialysis patients. Self-reported exhaustion was the initial indicator of frailty between CKD frail and hemodialysis frail group. Increasing age and age related cognitive impairment, depression, anemia, low GFR and having multi co-morbidities had a strong relation with frailty in patients with CKD.

\section{References}

1. Aguirre LE and Villareal DT (2015): Physical exercise as therapy for frailty. In Frailty: Pathophysiology, Phenotype and Patient Care; 83: 83-92.

2. Andersen K, Lolk A, Kragh-Sorensen P, et al. (2005): Depression and the risk of Alzheimer disease. Am J Epidemiol; 16:233-8.

3. Bao Y, Dalrymple L, Chertow GM, et al. (2012): Frailty, dialysis initiation, and mortality in end-stage renal disease. Archives of internal medicine; 172(14):1071-7.

4. Belza, B. L. (1995). Comparison of self-reported fatigue in rheumatoid arthritis and controls. The Journal of rheumatology, 22(4), 639-643.

5. Chaves PH, Carlson MC, Ferrucci L, et al. (2006): Association between mild anemia and executive function impairment in community-dwelling older women: The Women's Health and Aging Study II. J Am Geriatr Soc; 54(9):1429-1435.

6. Collard RM, Boter H, Schoevers RA et al. (2012): Prevalence of frailty in community-dwelling older persons: a systematic review. J Am Geriatr Soc; 60: 1487-1492.

7. Dowling TC (2007): Prevalence, etiology, and consequences of anemia and clinical and economic benefits of anemia correction in patients with chronic kidney disease: an overview. Am J Health Syst Pharm; 64(13): S3-S7.

8. El-Okl, M. A., El Banouby, M. H., and El Etrebi, A. (2002).Prevalence of Alzheimer dementia and other causes of dementia in Egyptian elderly.MD thesis, Faculty of Medicine, Ain Shams University. 
10. Fried, L. P., Tangen, C. M., Walston, J., Newman, A. B., Hirsch, C., Gottdiener, J., ... \& McBurnie, M. A. (2001). Frailty in older adults: evidence for a phenotype. The Journals of Gerontology Series A: Biological Sciences and Medical Sciences, 56(3), M146-M157.

11. Feng L, Nyunt MS, Feng L, et al. (2014): Frailty predicts new and persistent depressive symptoms among community-dwelling older adults: findings from Singapore longitudinal aging study. Journal of the American Medical Directors Association; 15(1):76-e7.

12. Hubbard RE, Lang IA, Llewellyn DJ, et al. (2010): Frailty, body mass index, and abdominal obesity in older people. Journals of Gerontology Series A: Biomedical Sciences and Medical Sciences; 65(4):377-81.

13. Johansen KL, Chertow GM, Jin C, et al. (2007): Significance of frailty among dialysis patients. Journal of the American Society of Nephrology; 18(11):2960-7.

14. Katz, S., Ford, A. B., Moskowitz, R. W., Jackson, B. A., \& Jaffe, M. W. (1963). Studies of illness in the aged: the index of ADL: a standardized measure of biological and psychosocial function. Jama, 185(12), 914-919.

15. Kouvelioti, V., Kellis, E., Kofotolis, N., \& Amiridis, I. (2015). Reliability of single-leg and double-leg balance tests in subjects with anterior cruciate ligament reconstruction and controls. Research in Sports Medicine, 23(2), 151-166.

16. Laursen TM, Munk-Olsen T, Nordentoft M, et al. (2007): Increased mortality among patients admitted with major psychiatric disorders: a register-based study comparing mortality in unipolar depressive disorder, bipolar affective disorder, schizoaffective disorder, and schizophrenia. The Journal of clinical psychiatry; 68:899-907.

17. Lawton, M. P., \& Brody, E. M. (1969). Assessment of older people: self-maintaining and instrumental activities of daily living. The gerontologist, 9(3_Part_1), 179-186.

18. Mansur HN, Colugnati FA, dos Santos Grincenkov FR, et al. (2014): Frailty and quality of life: a cross-sectional study of Brazilian patients with pre-dialysis chronic kidney disease. Health and quality of life outcomes; 12(1):1-7.

19. McCann K and Boore JR (2000): Fatigue in persons with renal failure who require maintenance haemodialysis. Journal of advanced nursing; 32(5):1132-42.

20. Metwally, A. S., El-Banouby, M. H., Mortagy, A. K., \& Ghanem, M. (1998). Prevalence of depression among Egyptian geriatric community. Faculty of Medicine, Ain Shams University. Shen Z, Ruan Q, Yu Z et al. (2017): Chronic kidney disease-related physical frailty and cognitive impairment: a systemic review. Geriatr Gerontol Int; 17: 529-544.

21. Mousavi S, Hayati F, Talebnejad M, et al. (2012): What is the difference between causes of ESRD in Iran and developing countries? Causes of end-stage renal disease in Khuzestan province is there any difference between causes of ESRD in developed and developing countries?. Shiraz E Medical Journal; 13(2):63-71.

22. Mulasso A, Roppolo M, Gobbens RJ, et al. (2017): Mobility, balance and frailty in community-dwelling older adults: What is the best 1-year predictor of falls?. Geriatrics \& Gerontology International; 17(10):1463-9.

23. Podsiadlo, D., \& Richardson, S. (1991). The timed "Up \& Go": a test of basic functional mobility for frail elderly persons. Journal of the American geriatrics Society, 39(2), 142148.

24. Roshanravan B, Khatri M, Robinson-Cohen C, et al. (2012): A prospective study of frailty in nephrology-referred patients with CKD. American Journal of Kidney Diseases; 60(6):912-21.

25. Sarnak MJ, Levey AS, Schoolwerth AC, et al. (2003): Kidney disease as a risk factor for development of cardiovascular disease: a statement from the American Heart Association Councils on Kidney in Cardiovascular Disease, High Blood Pressure Research, Clinical Cardiology, and Epidemiology and Prevention. Circulation; 108(17):2154-69.

26. Shen Z, Ruan Q, Yu Z et al. (2017): Chronic kidney diseaserelated physical frailty and cognitive impairment: a systemic review. Geriatr Gerontol Int; 17: 529-544

27. Song X, Zhang W, Hallensleben C, et al. (2020): Associations Between Obesity and Multidimensional Frailty in Older Chinese People with Hypertension. Clinical Interventions in Aging; 15:811-20.

28. Takeuchi H, Uchida HA, Kakio Y, et al. (2018): The prevalence of frailty and its associated factors in Japanese hemodialysis patients. Aging and disease; 9(2):192.

29. Wilhelm-Leen ER, Hall YN, Tamura MK, et al. (2009): Frailty and chronic kidney disease: the third national health and nutrition evaluation survey. The American journal of medicine; 122(7):664-71.

30. Xue QL (2011): The frailty syndrome: definition and natural history. Clinics in geriatric medicine; 27(1): 1-15 